follow-up of abnormal thyrotrophin (TSH) concentrations in the elderly in the United Kingdom. Clin Endocrinol 1991;34:77-83.

8 Snyder PJ, Utiger RD. Response to thyrotropin releasing hormone in normal man. 7 Clin Endocr 1972;34:380-5.

9 Caradoc-Davies TH, Loan P, Campbell AJ. Why are the sensitive TSH assay and TRH stimulation test frequently low in very old euthyroid subjects? and TRH stimulation test

10 Kaptein EM. Thyroid hormone metabolism in illness. In: Hennemann G, ed. Thyroid hormone metabolism. New York: Dekker, 1986:297-333.

11 Danforth $\mathrm{E}$. Effects of fasting and altered nutrition on thyroid hormone metabolism. In: Henneman G, ed. Thyroid hormone metabolism. New York: Dekker, 1986:335-57.

12 Piketty ML, Talbot NN, Askienazy S, Milhaud G. Clinical significance of a low concentration of thyrotropin: five immunometric "kit" assays compared Clin Chem 1987;33:1237-41.

13 Faber J, Kirkegaard C, Rasmussen B. Pituitary-thyroid axis in critical illness. F Clin Endocrinol Metab 1987;65:315-20.

14 Ehrmann DA, Weinberg M, Sarne DH. Limitations to the use of a sensitive assay for serum thyrotropin in the assessment of thyroid status. Arch Intern Med 1989;149:369-72.

15 Bacci V, Schussler GC, Kaplan TB. The relationship between serum triiodothyronine and thyrotropin during systemic illness. $\mathcal{f}$ Clin Endocrinol Metab 1982;54:1229-35.

16 Hay ID. Supersensitive thyrotropin assays. In: Hamburger JI, ed. Diagnostic methods in clinical thyroidology. New York: Springer-Verlag, 1989:39-61.

17 Spencer C, Eiger A, Shen D, Duda M, Qualls S, Weiss S, et al. Specificity of sensitive assays of thyrotropin (TSH) used to screen for thyroid disease in hospitalised patients. Clin Chem 1987;33:1391-6.

18 Morley JE. Neuroendocrine control of thyrotropin secretion. Endocr Rev $1981 ; 2: 396-436$

19 Re RW, Kourides IA, Ridgeway EC, Weintraub BD, Maloof F. The effect of glucocorticoid administration on human pituitary secretion of thyrotropin and prolactin. 7 Clin Endocrinol Metab 1976;43:338-46.

20 Helenius T, Liewendahl $\mathrm{K}$. Improved dialysis method for free thyroxin in serum compared with five commercial radioimmunoassays in non-thyroidal illness and subjects with abnormal concentrations of thyroxin binding globulin. Clin Chem 1983;29:816-22.
21 Liewendahl K, Tikanoja S, Helenius T, Valimaki M. Discrepancies between serum free triiodothyronine and free thyroxin as measured by equilibrium dialysis and analog radioimmunoassay in non-thyroidal illness. Clin Chem 1984;30:760-2

22 Chopra IJ, Chua-Teco GW, Mead JF. Relationship between serum free fatty acids and thyroid hormone-binding inhibitor in non-thyroid illnesses. $\mathcal{F}$ Clin Endocrinol Metab 1985;60:980-4.

23 Beckett GJ, Wilkinson E, Rae PWH, Gow S, Wu PS-C, Toft AD. The clinical utility of a non-isotopic two-step assay (DELFIA) and an analogue radioimmunoassay (SimulTRAC) for free thyroxine compared. Ann Clin Biochem 1991;28:335-44.

24 Stockigt JR, Stevens V, White EL, Barlow JW. "Unbound analog" radioimmunoassays for free thyroxin measure the albumin-bound hormone fraction. Clin Chem 1983;29:1408-10.

25 Gow SM, Elder A, Caldwell G. An improved approach to thyroid function testing in patients with non-thyroidal illness. Clin Chim Acta 1986;158:49-58.

26 Ekins R. Validity of analog free thyroxin immunoassays. Clin Chem 1987;33: 2137-52.

27 Spencer CA, Lopresti JS, Patel A, Guttler RB, Figen A, Shen D, et al. $\overline{\underline{\sigma}}$ Applications of a new chemiluminometric thyrotropin assay to subnormal $\overline{\bar{\omega}}$ Applications of a new enemiluminometric thyrotropin assay to subnormal $\frac{\sigma}{7}$

28 Beck-Peccoz P, Piscitelli G, Medri G, Ballabio M, Faglia G. Thyroid test $\stackrel{\mathbb{D}}{\varrho}$ strategy. Lancet 1985;i:1456.

29 Mori T, Imura H, Bito S. Clinical usefulness of a highly sensitive enzymeimmunoassay of TSH. Clin Endocrinol 1987;27:1-10.

30 Borst GC, Osburne RC, O'Brian JT, Georges LP, Burman KD. Fasting $\vec{\circ}$ decreases thyrotropin responsiveness to thyrotropin-releasing hormone: a potential cause of misinterpretation of thyroid function tests in the critically $\vec{\omega}$ ill. F Clin Endocrinol Metab 1983;57:380-3.

31 Griffin JE. Southwestern internal medicine conference: The dilemma of abnormal thyroid function tests-is thyroid disease present or not? Am f Med Sci 1985;289:76-88.

32 Engler D, Donaldson EB, Stockigt JR, Taft P. Hyperthyroidism without triiodothyronine excess: an effect of severe non-thyroidal illness. 7 Clin Endocrinol Metab 1978;46:77-82.

\title{
Personal computer software for handling references from CD-ROM and mainframe sources for scientific and medical reports
}

\author{
Richard G Jones
}

\section{Department of Chemical Pathology and Immunology, University of Leeds, Leeds LS2 9JT} Richard Jones, senior lecturer

$B M \mathcal{B} 1993 ; 307: 180-4$
Most practising medical scientists are now familiar with the use of computer based literature searches as a preliminary source of data in a programme of research. For most the searches will probably have been conducted by a library assistant skilled in the use of medical databases. ${ }^{1-4}$ Of late, access to data sources such as MEDLINE, either through mainframes or from CD-ROMs, has become easier, and more people are now able to conduct their own searches. ${ }^{25-7}$ Whatever the method used a persistent problem has always been how to handle the large volume of data generated. If results are provided on paper they are difficult to organise systematically and often require repeated retyping and refiling in manual systems.

The inefficiency of such an approach becomes most obvious in writing papers or completing theses, when the relevant references must be painstakingly and accurately recompiled in the new manuscript, taking account of the lack of standardisation in journal requirements. Indeed compiling and formatting the bibliography of a thesis must class as one of the most soul destroying undertakings of a scientific training. Help is now at hand, however, in the form of a number of excellent packages for personal computers, which help in storing and organising references and also the automatic compilation of bibliographies formatted in appropriate styles (appendix 1) ${ }^{8-12}$ Furthermore these packages can accept data directly from mainframe and CD-ROM sources, thus enabling a seamless cycle from database search through assimilation to the referencing of a new scientific manuscript.

I describe here the components of the process and the links between them and will briefly review a selection of the packages available.

are MEDLINE and Excerpta Medica. These databases 0 are updated by their owners each month with new medical publications and are then made available to $\overline{0}$ users. Access can either be online to a mainframe host $\frac{\otimes}{\varnothing}$ computer or through a locally held CD-ROM version $\varnothing$ of the database..$^{213}$ The mainframe host computer will $\overrightarrow{\overrightarrow{0}}$ update its database continually, and users gain direct 3 access to the database via telephone networks and pay for time spent connected to the database. CD-ROM versions are copies of the main database made periodically (say every three months) and sold to end users, who pay a yearly subscription. Once the user:(usually a library) has bought the CD-ROM it can be 3 . accessed at no further cost, via a CD-ROM drive 8 attached to a personal computer. In both cases the database may be available from a number of different $\mathrm{O}$ information vendors, each of whom, though supplying the same basic data, may offer it with other services and $\sigma$ facilities. Alternative sources include the disk based $\frac{D}{0}$ version of Current Contents, which is issued weekly and is provided with its own retrieval software.

For some years the Swiss company Radio-Suisse has

Examples of some available databases and sources

\begin{tabular}{|c|c|c|}
\hline Database name & Description & Hosts \\
\hline Biosis Previews & $\begin{array}{l}\text { Major database on biological } \\
\text { sciences }\end{array}$ & $\begin{array}{l}\text { Datastar, } \\
\text { DIALOG, } \\
\text { ESA-IRS }\end{array}$ \\
\hline Excerpta Medica & $\begin{array}{l}\text { Major medical database biased } \\
\text { towards drugs and European } \\
\text { publications }\end{array}$ & $\begin{array}{l}\text { Datastar, } \\
\text { DIALOG }\end{array}$ \\
\hline Martindale & Pharmacopoeia online & $\begin{array}{l}\text { Datastar, } \\
\text { DIALOG }\end{array}$ \\
\hline MEDLINE ${ }^{\star}$ & $\begin{array}{l}\text { Index Medicus plus abstracts, } \\
\text { overlaps by only } 30 \% \text { with } \\
\text { Excerpta Medica }\end{array}$ & $\begin{array}{l}\text { Datastar, } \\
\text { DIALOG } \\
\text { BLAISE-LINK }\end{array}$ \\
\hline Toxline & Big toxicology database has & Datastar \\
\hline
\end{tabular}

\section{Data sources}

There are many available data sources of medical reports (table). The two most widely used databases

$\begin{array}{lll} & \begin{array}{l}\text { about } 12000 \text { new records a } \\ \text { month }\end{array} & \\ \text { Current Contents } & \begin{array}{l}\text { Floppy disk format, includes } \\ \text { database search facility }\end{array} & \text { Floppy disk }\end{array}$
\section{$x^{2}$}


been a leading supplier of information in Europe offering both MEDLINE and Excerpta Medica in its DataStar service. In the United States the National Library of Medicine has been a major host supplier. Other suppliers include Maxwell Online, through the BRS Colleague service, which is available internationally via a network of host systems (appendix 2). ${ }^{14}$ The choice of vendor is determined on the basis of ease of access, cost, and the range of services. ${ }^{1}$ The latter may include help systems, user friendly search languages, and, in the case of some systems, direct access to full text databases of leading journals such as the Lancet, and New England Fournal of Medicine, and BMF. ${ }^{15}$ Costs are incurred in a number of ways with these systems and tend to rise in proportion to the number of facilities. They include telephone charges for dial up access by using modems, network charges when using systems such as DialPlus (BT), connect time fees, and charges for accessing, printing, and downloading citations identified in the searches. For academics access via academic networks (in the United Kingdom JANET) can offer substantial savings as telephone and network charges are underwritten centrally.

The choice of CD-ROM supplier is made on similar grounds of cost and availability but is also likely to be influenced by the questions of hardware support and access to other CD-ROM titles such as atlases, encyclopaedias, and medical texts such as the Oxford Textbook of Medicine or the Multi-media Encyclopaedia of Mammalian Biology.

\section{MAINFRAME V CD-ROM}

The choice between the mainframe or CD-ROM as primary source is likely to be influenced by several other factors. At present CD-ROMs have limited capacity: five years of data fill three disks. Therefore extended searches can be accomplished only by swapping disks, unless a CD-ROM jukebox is available. If such searches are needed regularly online access may be preferable. Similar arguments exist regarding disk based issues of Current Contents, where, though individual disks contain current information, searching in depth is difficult. The mainframe systems tend to be faster than the CD-ROM, especially for complex searches. Furthermore, the updates to the CD-ROMs tend to lag the mainframes by about three months, so if up to the minute information is required online access is preferable.

CD-ROMs do have several potential advantages. ${ }^{6}$ Because connect time is inexpensive (and usually free) more time can be spent browsing the system, unexpected references often being found which might have been missed with a mainframe search limited by time. Similarly, searches can be constructed iteratively, and this can help to increase the yield of useful data. The human-computer interfaces of personal computer systems also tend to be better designed and therefore easier to use than those on the mainframe systems and include a greater depth of help for the construction of complex searches. This can be a great advantage to infrequent users as the programmes can usually be run without extensive training and the skills relearned more easily. Finally there is no need to understand computer communications before being able to contact the database.

Modems, network gateways, and communications software can present a very intimidating and frustrating barrier for a beginner with no desire to become a computer "hacker." A recent survey identified that up to $11 \%$ of searches proved unproductive because of system or telecommunications failures, ${ }^{16}$ a figure which for most new users would be unacceptable.

FIG 1 - Complete process of transferring references from online or CD-ROM sources through personal computer databases and into finished manuscripts
Features of bibliographic databases for personal computers

- Electronic storage of references

- Annotation of references

- Sorting and selection by using keywords, authors, dates, etc

- Importation of references from mainframe/ CD-ROM data sources

- Automatic generation of bibliographies

end result will be a list of references with or without their abstracts. In the past this usually took the form of a printout, which for big searches could run to several pages. Though useful as a list for finding references in the library, any further use of the references-for example, for inclusion in a reading list or bibliography -required them to be laboriously retyped. With the advent of bibliographic databases on personal computers it is now usual for the list to be available as a file which can be transferred from the host system, whether CD-ROM or mainframe, on to the personal computer. ${ }^{15}$ At their simplest these files can be handled by standard word processors and can be edited or reorganised before printing. Once on the personal computer, however, the files can then be read by the bibliographic systems and the data incorporated into the owner's own local database. This not only obviates the need for retyping but also allows many other features of the bibliographic systems to be used.

\section{Bibliographic systems}

The available systems have evolved over the past decade in parallel with the increasing availability of personal computers. They have largely originated as programs developed by practising scientists or librarians and provide many facilities well adapted for academic use. Indeed, most of the available systems provide comprehensive database functions to facilitate and support scientific use of the literature (see box). These include the ability to reindex retrieved references, to sort and search selectively through them, and, in most cases, to add extensive notes for storage within the database. In addition, some systems allow indexing of reprint collections and some even automatically print reprint request cards for dispatch to the appropriate author.

Such features can be exploited for many different purposes beyond the maintenance of a personalised database of the literature. When run on local area networks many users can share the same database, allowing small research teams to maintain a common bibliographic source, which can facilitate interaction and reduce fruitless repetitive searching. Similarly, such shared access can be used to support teaching by allowing access by students to appropriately constructed databases. At the other extreme the database managers can be run on notebook sized portable personal computers and carried into libraries, where notes can be edited directly onto the database.

\section{Bibliography generation}

By far the most time saving feature of these systems, however, is their ability to generate correctly sequenced and formatted bibliographies for scientific papers. ${ }^{8} \mathrm{~A}$ draft word processed manuscript can be scanned by these systems to identify the citations it contains. These can then be retrieved from the database, formatted, and tailored as required for particular journal or book (fig 1). 
FEATURES

The method of incorporating citations into the draft manuscript entails linking the citations in the text with the references in the database. Most systems give each reference a unique identification number or code within the database (fig 2 shows examples). This identifier is placed within the text at the relevant citation point. Once the draft manuscript is complete a program is run which reads these identifiers, extracts the references from the database, and compiles them into a bibliography. The format of the references in the latter can be automatically adjusted to that required by the journal for which the manuscript is intended (figs $3 a$ and $3 b$ ). At the same time the identifiers in the draft manuscript are updated to the format required for the final document (fig 4). These might be in numerical

\section{(a)}

While there is some controversy on this point $\{176\}$ most authors feel that the traditional methods are still valid $\{35$, $198\}$

(b)

While there is some controversy on this point [Smith, 1985 \#4] most authors feel that the traditional methods are still valid $\{$ Davies, 1987, hplc; Flinder, 1988, ria .

IG 2-Examples of two types of identifier used to indicate reference within manuscript. (a) Reference Manager, (b) Endnote

\section{(a)}

Davies, D.P., Lasky, L.C., Keller, R.M., and Morrison, D.S. (1982) A system for the measurement of drug break down products using HPLC. Am. f. Clin. Path. 78, 722-727.

Flinder, R. (1988) Emergency therapeutic drug analysis using a novel RIA for benzodiazepines. Ann. Intern. Med. 17(9),

921-926.

Smith, M.J. and Cooper, R.W. (1975) Volatile drug metabolites detected by bedside mass spectrometry. $\mathrm{Br}$. Med. f. 2, 585-591.

(b)

1. Smith, M.J. and Cooper, R.W. Volatile drug metabolites detected by bedside mass spectrometry. Br Med J 1975;2:585-591.

2. Davies, D.P., Lasky, L.C., Keller, R.M., and Morrison, D.S. A system for the measurement of drug breakdown products using HPLC. Am J Clin Path 1982;78:722-727.

3. Flinder, R. Emergency therapeutic drug analysis using a novel RIA for benzodiazepines. Ann Intern Med 1988;17:921-926.

FIG 3-Two examples of same references automatically generated in styles appropriate for different journals. (a) Formatted for "fournal of Comparative Neurology," (b) Formatted for "Clinical Chemistry"

or the more traditional "author, date" style, and formatting controls such as superscripts can be automatically applied for the most widely used word processors. Should there be a need to resubmit a paper to a different journal at a later date a new bibliography in a completely different format can be generated without the need for retyping by simply repeating the process but using the new target style. Similarly, if references are to be added or deleted this can be done without the need to readjust manually identifiers and bibliographies.

The sophistication of the available personal computer packages varies considerably, reflecting the different degrees of commercial redevelopment of the original systems. Though all provide basic facilities, some offer features which considerably enhance their use..$^{1015}$ Some are able to scan manuscripts, compiling bibliographies on the basis of free text entries in-for example, author, year format. This obviates the need to enter unique identifiers, but manual selection and confirmation and selection of database entries may be necessary. Similarly the flexibility in relation to the (a) While there is some controversy on this point (Smith \& Cooper, 1975) most authors feel that the traditional methods are still valid (Davies et al, 1982; Flinder, 1988).

(b)

While there is some controversy on this point (1) most authors feel that the traditional methods are still valid $(2,3)$.

FIG 4-Examples of different styles of citation markers which can be automatically generated by these programs. (a) Formatted for "Fournal of Comparative Neurology," (b) Formatted for "Clinical Chemistry"

formats of the generated citation styles is greater with some packages than with others. For example, while all support numbered (for example, (1)) and author and year (for example, (Smith et al, 1982)) styles some allow extra formatting control including subscripts and superscript and the ability to include page numbers (for example, (Smith et al, 1982; 27p)). Some even provide the ability to control the order of citations within a group-for example, alphabetical (Jones, 1985; Smith, 1987; Zieve, 1982) or chronological (Zieve, 1982; Jones, 1985; Smith, 1987). The cost of increased flexibility, however, is usually complexity of use, and for general users a compromise between adequate functionality and ease of use must be made.

Most systems are fully compatible with the more popular word processors-for example, Microsoft Word, Wordperfect, Wordstar. By the use of small "terminate and stay resident" programs some can be fully integrated with these word processors and can be run simultaneously. These programs are run just before running the word processors and lie dormant in memory until activated by a unique keystroke sequence-for example, Control-Alt-r. The word processor can then be run to allow normal text editing to proceed. At points where citations are required the citation program can be activated. Once activated the program appears on screen as a pop up window overlaying the word processing screen. Direct access to the reference database is then possible while the text of the manuscript is still visible on the screen. References can then be scanned within the database so that searches can be made to find appropriate sources. Once found the unique citation identifiers can be automatically inserted into into the manuscript before control is returned to the word processor. This avoids the need to be constantly swapping between programs and makes the process of referencing a manuscript almost painless

CHECKLIST

Given the range of available packages and their varying degree of sophistication and cost how does one choose between them? The box provides a check list of

Ten key questions to ask when selecting a system

1 Is it compatible with my word processor?

2 Will it coexist with my word processor as a terminate and stay resident program?

3 Will it automatically generate bibliographies in the styles I need?

4 Can the system import from major reference sources?

5 Will it allow customisation of import and export formats?

6 Is it easy to use?

7 How good is the user manual?

8 What mechanism of linkage does it use between the manuscript and the database?

9 Will it support group usage?

10 How much does it cost to get all the features need? 
10 basic features which can be used to examine and compare the systems. The relative importance of each feature will differ depending on the intended use and the ability of the user. Novice users may prefer menu driven systems which could infuriate the experienced computer buff. Similarly for group work network compatibility might be an important and overriding factor. As a minimum packages should be capable of importing data from the main reference sources (for example, MEDLINE), they should be able to read manuscript files in the format of the user's word processor, and they should be able to produce citation marks in both numeric and author, year formats and bibliographies in styles suitable for relevant major journals, including Vancouver style.

\section{As essential as the word processor?}

Does the use of these packages improve the quality of the finished manuscripts? The simple answer must be no. The fundamental requirements of good papers remain the same: solid science, clear thinking, well written prose, high quality informative illustrations, and scholarship. Indirectly, however, these systems can help. They alleviate many of the chores, allowing authors to concentrate more on content. They encourage selective and systematic use of published reports and from the editor's point of view must help in eliminating detailed errors in format and content of bibliographies.

Do they aid clinical decision making? Again the answer may be no, though this may be because to date access and appropriate training has been lacking. ${ }^{317}$ In a period when time is becoming ever more scarce their use to support research and clinical practice is likely to become commonplace and, dare I say, as essential as that of the word processor. ${ }^{318}$

This article was prepared at the request of the scientific developments subcommittee of the Association of Clinical Biochemists, but the views expressed are mine. I thank all the software suppliers who provided the packages included in this review and Maxwell Online for free access to Colleague. I am grateful for the helpful comments of the scientific developments subcommittee of the Association of Clinical Biochemists and Dr Julian H Barth.

\section{Appendix 1}

\section{Some available microcomputer packages}

The list includes systems advertised in major scientific journals or known to be in widespread general use. All suppliers who were invited to submit packages did so and provided excellent support.

\section{Pro-Cite}

Personal Bibliographic Software Inc, 535 Avis Drive, Suite 10, Ann Arbor, Mississippi 48108, United States.

$\mathrm{Tel}+1$ (313) 996-1580

Cost $£ 300$

Pro-Cite is a professional bibliographic system available for both IBM compatible personal computers and Macintosh. It is part of a family of products, PRO-SEARCH and BIBLIOLINKS, which support mainframe searching and downloading. It is enormously flexible, being configurable to store any information which could be conceivably required in a bibliography, including books, chapters, papers, personal communications, reports, and even slides. The downside of the flexibility is that the interface is fairly complex and could be confusing for casual users. The linkage packages for importing references are not included in the basic price.

\section{Papyrus}

Research Software Design, 2718 SW Kelley St, Suite 181, Portland, Oregon 97201 , United States.

$\mathrm{Tel}+1$ (503) 796-1368

Cost $£ 99$

Papyrus is a very powerful and cost effective bibliographic system. It is flexible and configurable and can accommodate a wide variety of sources of material including audiovisual material and slides. The user interface is a little idiosyncratic and it requires more skill to run than do some other systems. It is fully compatible with PRO-CITE and offers an alternative of similar specification. A comprehensive and easy to use manual is provided.

\section{Endnote}

Cherwell Scientific Publishing, 27 Park End Street, Oxford OX1 $1 \mathrm{HU}$

Tel 0865784800

Cost $£ 114$

Endnote is a single user bibliographic database available on IBM and Macintosh systems. It is fully menu driven by using standard windowing techniques. Though not as powerful as some of the more expensive systems, it is easy to learn and offers facilities which would more than satisfy most users. To incorporate references from online systems a companion package ENDLINK is required, which is an extra cost. This was not available for review. The manual is clear and well presented. In summary, an attractive and easy to use package.

\section{Paperbase Deluxe}

Wight Scientific, 44 Roan Street, London SE10 9JT.

Tel 0818582699

Cost $£ 90$

Paperbase Deluxe is the product of several years of development of a bibliographic system designed by an active research worker. Though lacking some of the sophistication of the more expensive products it functions adequately and is well supported by the supplier. The main weakness of the review copy was the user interface, but the newly revised data editor suggests that this will soon be radically improved. As Paperbase is in a continual process of development, with upgrades available to users at nominal cost, it offers a low cost solution for individual users.

\section{Reference Manager}

Research Information Systems Inc, Bilaney Consultants Ltd, St Julians, Sevenoaks, Kent TN15 0RX.

Tel 0732450002

Fax 0732450003

Cost $£ 300$

Reference Manager is a mature commercial system well adapted to medical science. The interface is menu driven with clever use of windowing techniques to support most functions. It is extremely powerful with good database functions and scope for extensive customisation. It comes configured for use with all the major sources of bibliographic information. It has some limitations in respect of the reference types it can store (for example, slides, patents) but compensates for this through its ease of use. It supports terminate and stay resident integration with popular word processors such as Wordperfect and Microsoft Word. A Windows version is available.

\section{Autobiblio}

Biosoft, 22 Hills Road, Cambridge CB2 1JP.

Tel 022368622

Fax 0223312873

Cost $£ 125$

Available for Macintosh only. Not reviewed but system description seems comprehensive.

\section{Refsys Super}

Biosoft, 22 Hills Road, Cambridge CB2 1JP.

Tel 022368622

Fax 0223312873

Cost $£ 125$

A fairly simple system from Biosoft. It is easy to use with a convenient built in manual available on a series of help screens. It lacks the sophistication of other packages, particularly in relation to its handling of keywords. The automatic bibliography generation function is cumbersome, requiring more manual editing than should be necessary.

\section{Appendix 2}

\section{Sources for major databases}

MAINFRAME HOSTS

BLAISE-LINK - The British Library, 2 Sheraton Street, London W1V 4BH. Tel 0716361544. 
DATASTAR - Data-Star, 5th Floor Plaza Suite, 114 Jermyn Street, London SW1Y 6HJ. Tel 0719305503.

MAXWELL ONLINE-BRS Colleague, Achilles House, Western Avenue, London W3 0UA. Tel 081992 3456. Fax 0819937335 .

DIALOG-Dialogue Informations Services, PO Box 8, Abingdon, Oxford OX13 6EG. Tel 0865326326.

CURRENT CONTENTS-Institute for Scientific Information, Brunel Science Park, Brunel University, Uxbridge UB8 3PQ. Tel 0895230085.

ESA-IRS - C P 64 Via Galileo Galilei, 00044 Frascati, Italy. STN INTERNATIONAL-PO Box 2465, D-7500 Karlsruhe 1, Germany.

THE BRITISH LIBRARY: ONLINE SEARCH CENTRE -25 Southampton Buildings, London WC2A 1AW. Tel 071 3237477 .

MEDICAL INFORMATION SERVICE-Document Supply Centre, Boston Spa, Wetherby LS23 7BQ. Tel 0937 546000/84343. Fax 0937546333.

CD-ROM SUPPLIERS

SILVERPLATTER INFORMATION INC-10 Barley Mow Passage, Chiswick, London W4 4PH. Tel 0819958242. Fax 0819955159

GLOBAL COMMUNICATIONS-Albermarle House, Osborne Road, Southsea, Hants PO5 3LB. Tel 0705291866. Fax 0705821677.

OPTECH LTD-East Street, Farnham, Surrey GU9 7XX. Tel 0252714340 . Fax 0252711121

NETWORK SERVICES

JANET (Joint Academic Network)--JANET Network Executive, c/o Rutherford-Appleton Laboratory, Chilton, Didcot OX11 0QX. Tel 0235445637.
DIALPLUS - GNS, BT, Network House, Brindley Way, Hemel Hempstead HP3 9RR. Tel 0800181555

1 Scheidt SS, Goldstein H, Blackburn IS. Application of the office or hom computer to searching the medical literature. I Am Coll Cardiol 1986; $211-7$

2 Wallingford KT, Humphreys BL, Selinger NE, Siegel ER. Bibliographic retrieval: a survey of individual users of MEDLINE. MD Comput 1990; 166-71.

Ludwig L, Mixter JK, Emanuele MA. User attitudes toward end-user literature searching. Bull Med Libr Assoc 1988;76:7-13.

4 McKibbon KA, Haynes RB, Dilks CJ, Ramsden MF, Ryan NC, Baker L, et al. How good are clinical MEDLINE searches? A comparative study of clinical end-user and librarian searches. Comput Biomed Res 1990;23: 583-93.

5 Wyat J. Computer-based knowledge systems. Lancet 1991;338:1431-6.

6 Wyatt J. Use and sources of medical knowledge. Lancet 1991;338:1368-73.

Bonham MD, Nelson LL. An evaluation of four end-user systems for searching MEDLINE. Bull Med Libr Assoc 1988;76:22-31.

8 Garfield JM, Flanagan H, Fox J. A comparison of two microcomputer-based programs for bibliographic retrieval and formatting. I Clin Monit 1989;5: $177-85$

9 Simon FA. A comparison of two computer programs for searching the medical literature. Fournal of Medical Education 1988;63:331-3.

10 Rosenberg V. Pro-Search, Biblio-Links and Pro-Cite: software to gather and manage scientific and technical information. Biotechniques 1991;10:796-7.

11 Schmid K, Bohmer G. Reference master: a microcomputer-based storage and retrieval system for bibliographic references. Int f Biomed Comput 1987;20: $107-21$.

BMf 1986;292:1643-5

3 Wertz RK. CD-ROM. A new advance in medical information retrieval. $\varsubsetneqq A M A$ 1986;256:3376-8.

14 Bowler RP, Becker CE Computer searching for occupational medicine $f$ Occup Med 1986;28:370-2.

15 Haynes RB, McKibbon KA, Fitzgerald D, Guyatt GH, Walker CJ, Sackett DL. How to keep up with the medical literature. V. Access by personal computer to the medical literature. Ann Intern Med 1986;105:810-6.

16 Walker CJ, McKibbon KA, Haynes RB, Ramsden MF. Problems encountered by clinical end users of MEDLINE and GRATEFUL MED. Bull Med Libr Assuc 1988; 79:67-9.

17 Nussey SS, Lyon E. The clinical 'end user'-a neglected resource in patient care? I R Coll Physicians Lond 1990;24:119-22.

18 Haynes RB, McKibbon KA, Walker CJ, Ryan N, Fitzgerald D, Ramsden MF. Online access to MEDUINE in clinical settings. A study of use and usefulness. Amn Intern Med 1990;112:78-84.

(Accepted 5 May 1993)

\title{
Neuroleptics, learning disability, and the community: some history and mystery
}

\author{
David Manchester
}

Recent papers have again highlighted the consistently high use of neuroleptic agents among people with a learning disability, despite the lack of good evidence to support their role in this population for behaviour management and despite the risks of such medication. Evidence suggests, however, that prescribing habits have remained relatively unchanged; the reasons for this are poorly understood. Given the lack of understanding about the factors contributing to such drug use, and the possibility that use of neuroleptics will increase as people with learning disabilities move into the community, there seems a clear need for clinical guidelines to cover the prescribing and monitoring of neuroleptics within this group. Such guidelines should also ensure that reviews, using reliable measures of treatment efficacy, are carried out regularly.

For the sake of clarity the term learning disability is used throughout this paper and replaces the various other terms (for example, mental handicap, mental retardation, and developmental disability) used to describe the same client population in some of the papers mentioned.

Selinical Psychol Services, Clifton Hospital, York YO3 6RD

David Manchester, clinical psychologist in learning disabilities

BMY 1993;307:184-7 estimated that most people with a learning disability receive one or more drugs to control behaviour, including stimulants, anticonvulsants, antidepressants, major tranquillisers, and anxiolytics. ${ }^{5}$ Overall, those most commonly used in managing behaviour are neuroleptics. In a recent review of 168 people with learning disabilities living in hospital, $49 \%$ were receiving neuroleptic medication. ${ }^{3}$

Standard psychopharmacology text books assert that the clearest indication for the use of neuroleptic medication is to treat psychiatric disorders, where the symptoms they aim at decreasing are causing suffering and disability for the client. ${ }^{6}$ Estimates for serious psychiatric disorders in people with learning disabilities range from $8 \%$ to $15 \% .^{7}$ One recent American survey of over 40000 people with learning disabilities living in hospital or in the community noted a prevalence for psychoses of $6.68 \%$ in people under 22 years of age and of $5.69 \%$ in people aged 22 years and over. ${ }^{8}$ The incidence of shizophrenia alone has been estimated as $3.4 \%$ among hospital residents. ${ }^{\circ}$

Although there is a consensus that the prevalence of psychiatric illness in people with learning disabilities is greater than that in the general population, the true rate is notoriously difficult to verify. This is partly because people with severe to profound disability are unlikely to be able to give adequate or reliable self reports, and partly because most studies have concentrated on hospital populations, which are by definition unrepresentative of the client group as a whole. Studies on this topic have also been criticised for using vague 